\title{
A Nova Ordem Repressiva
}

The New Repressive Order

El Nuevo Orden Represivo

Paulo Roberto Ceccarelli

Pontifícia Universidade Católica de Minas Gerais

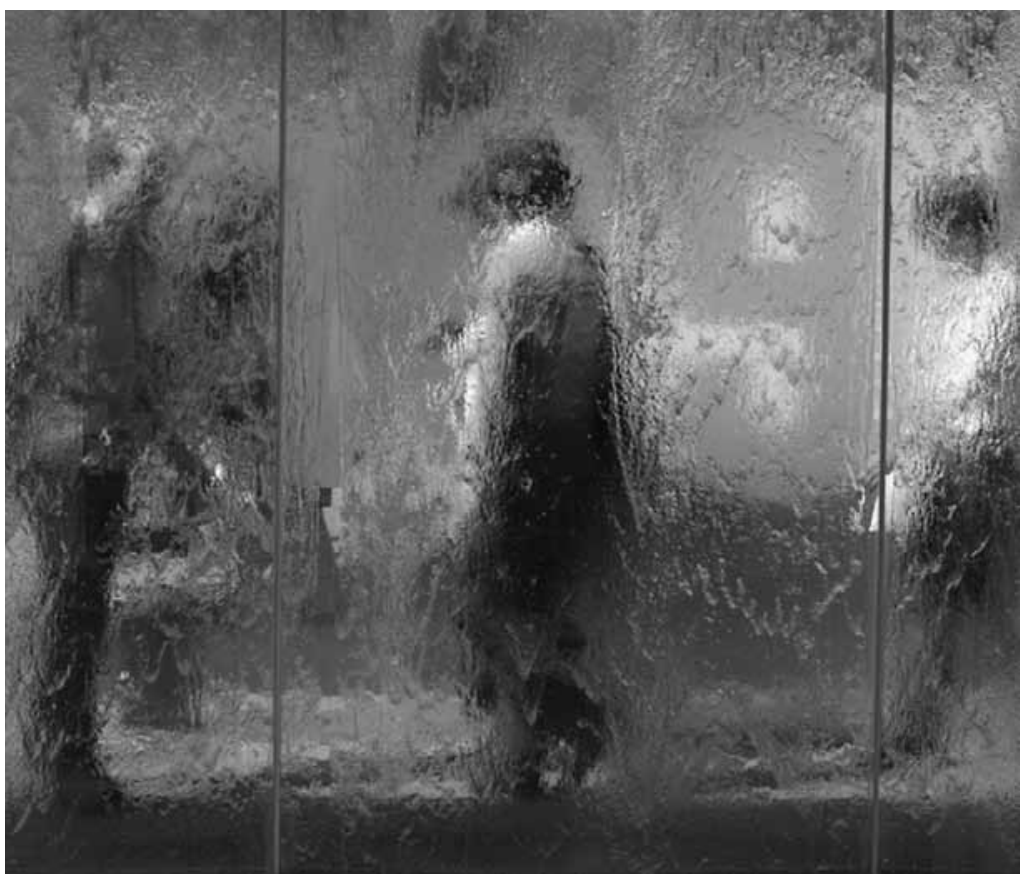


Resumo: Segundo o autor, a humanidade sempre foi marcada por alguma forma de controle de acordo com o discurso do momento sociohistórico que atravessa: esse texto discute alguns instrumentos de controle e repressão da contemporaneidade. Se, por séculos, foi a religião que ditou as normas sociais, na modernidade, as verdades religiosas foram substituídas por enunciados científicos que sugeriam uma linearidade histórica e propunham uma compreensão determinista do mundo, baseada na capacidade da ciência em dar respostas. As certezas da modernidade foram radicalmente questionadas na pósmodernidade, fazendo surgir outros mecanismos de controle. Para o autor, a necessidade do ser humano de criar representações e dispositivos para suportar e nomear a angústia inerente ao desamparo que lhe é próprio o leva a submeter-se aos mais variados discursos repressivos. O discurso científico atual vem sendo transformado em instrumento ideológico que, com as inúmeras expressões do politicamente correto, traduzem uma busca de normatização e de padronização de comportamentos, gerando uma nova ordem repressiva. No que diz respeito à saúde psíquica, os manuais de diagnóstico, financiados pela indústria farmacêutica, transformam comportamentos, individualidades e diversidades em patologias: as singularidades tornam-se anormalidades. Qual é o compromisso social dos psicólogos nesse debate?

Palavras-chave: Repressão. Psicopatologia. Compromisso social. Atuação do psicólogo.

Abstract: According to the author, some form of control according to the discourse of the social-historical moment we are going through has always marked humanity. This text discusses some contemporaneous instruments of control and repression. If religion has dictated the social norms for centuries, in modernity religious truths have been substituted by scientific statements that believed in historical linearity and conceived the world in a determinist way, based on the capacity of science on giving answers. Post-modernity has radically questioned the certitudes of modernity, which made appear new mechanisms of control. For the author, the necessity of the human being to create representations and devices to support and to nominate his/her inherent anguish leads him/her to submit himself/herself to a large variety of repressive discourses. Current scientific discourse, alongside with the many expressions of the "politically correct", became an ideological instrument that express the search for normalization and standardization of behaviors, which generates a new repressive order. Concerning psychic health, the diagnosis manuals, supported by the pharmacological industries, transformed behaviors, individualities and diversities into pathologies and, at the same time, singularities into abnormalities. Which is the social commitment of psychologists in this debate? Keywords: Repression. Psychopathology. Social commitment. Psychologist performance.

Resumen: Según el autor, la humanidad siempre fue marcada por alguna forma de control de acuerdo con el discurso del momento socio-histórico que atraviesa: ese texto discute algunos instrumentos de control y represión de la contemporaneidad. Si, durante siglos, fue la religión quien dictó las normas sociales, en la modernidad, las verdades religiosas han sido substituidas por enunciados científicos que sugerían una linealidad histórica y proponían una comprensión determinista del mundo, basada en la capacidad de la ciencia en dar respuestas. Las certezas de la modernidad fueron radicalmente cuestionadas en la posmodernidad, haciendo surgir otros mecanismos de control. Para el autor, la necesidad del ser humano de crear representaciones y dispositivos para soportar y nombrar la angustia inherente al desamparo que le es propio lo lleva a someterse a los más variados discursos represivos. El discurso científico actual viene siendo transformado en instrumento ideológico que, con las innumerables expresiones de lo políticamente correcto, traducen una busca de normatización y de padronización de comportamientos, generando un nuevo orden represivo. En lo que dice respecto a la salud psíquica, los manuales de diagnóstico, financiados por la industria farmacéutica, transforman comportamientos, individualidades y diversidades en patologías: las singularidades se tornan anormalidades. ¿Cuál es el compromiso social de los psicólogos en ese debate? Palabras clave: Represión. Psicopatología. Compromiso social. Actuación del psicólogo.

Ao propor como título deste trabalho A nova ordem repressiva, minha intenção foi a de refletir sobre uma forma de controle que vem ganhando espaço e fazendo-se presente em nosso cotidiano e em nossa prática profissional. Entendo por ordem repressiva toda forma discursiva que, apoiada ou não no saber científico, gera regras sociais e normas de conduta que servem para classificar, etiquetar, punir, enfim, para determinar como os sujeitos devem proceder de acordo com um suposto projeto coletivo, ou ainda, com uma natureza humana. Regimes totalitários e fascistas não escondem a imposição de uma ordem repressiva a ser seguida sem questionamentos. Em 
... a verdade é uma invenção interpretativa, cujos conceitos são datados,

e que dura até que uma outra verdade venha substituí-la (Foucault, 2000). outros regimes, o discurso repressivo é mais camuflado, e, muitas vezes, utiliza-se do saber científico para validar suas posições. Não raro, como tentarei mostrar, esse saber científico, altamente comprometido, quando não subvencionado por aqueles que detêm o poder, é transformado em instrumento ideólogo para justificar as medidas a serem tomadas.

Estamos de tal forma submersos nas normas que determinam e controlam a nossa inserção social que não percebemos que elas respondem a construções que são apresentadas como verdades imutáveis, porém a verdade é uma invenção interpretativa, cujos conceitos são datados, e que dura até que uma outra verdade venha substituí-la (Foucault, 2000). A necessidade de verdades, disfarçadas em regras de conduta que podem levar a uma forma de controle, parece ter nos acompanhado desde os primórdios da humanidade. Para alguns, elas têm o mesmo estatuto que Freud atribui à ilusão: "Se ela se tornar desacreditada - e, na verdade, a ameaça disso é bastante grande - então o mundo desmoronará. Nada lhe resta (ao indivíduo) a não ser desesperar de tudo, da civilização e do futuro da humanidade" (Freud, 1927/1974, p. 69). Gostaria de começar minha argumentação por uma pequena digressão histórica para esclarecer o que entendo por controle e para melhor compreender essa necessidade, senão fatalidade, inerente ao ser humano.

Sem a supressão, ainda que parcial, das pulsões sexuais e agressivas, a própria cultura não poderia existir (Freud, 1908/1969b). Como mostra Foucault na História da Sexualidade, a sociedade sempre esteve sujeita a alguma forma de controle para garantir a supressão pulsional. O discurso sobre a regulação dos costumes e da sexualidade, com todo o sexismo, machismo e misoginia que ele comporta, sempre foi prerrogativa das elites dominantes, da religião e do Estado. É claro que uma certa tolerância sempre existiu em todas as sociedades - a partir de regras extremamente variáveis - desde que esta Ihes fosse útil (Flandrin, 1986). Não existe nenhuma sociedade que não tenha estabelecido limites relativos ao uso da libido. Os trabalhos de Sociologia e os de Antropologia sugerem que uma certa retenção em relação aos prazeres tem sido, em intensidade variável, um elemento constitutivo do psiquismo humano, ou seja, regular os costumes e o prazer parece ser uma astúcia inerente ao trabalho de cultura (Kulturarbeit), no sentido freudiano do termo, para manter a coesão dos grupos humanos.

Nas sociedades controladas pela religião, cabe aos sacerdotes, inspirados na vontade dos deuses, ditar as normas de conduta. Foi assim que, no início da era cristã, o mundo foi organizado em escalas de valores de acordo com um projeto divino inescrutável, sem possibilidade de mudanças: a Terra era o centro do universo, o homem a mais perfeita criação de Deus, seguido de perto pela mulher, e a religião oferecia as referências ético-morais a serem seguidas. A única coisa a fazer era manter o que já estava pronto. Ainda hoje, um discurso fundamentalista baseado na Verdade continua sendo utilizado em vários países, muitas vezes pela via do terrorismo, para manter o controle.

A visão sagrada do mundo foi secularizada, e a religião substituída pela ciência, cujo ideal era a objetividade. Para a Física clássica, tudo tinha uma causa específica e um efeito previsível, ou seja, o mundo poderia ser compreendido de forma rigorosa e determinista, o que levou à divisão eu e mundo. "Em consequência da divisão cartesiana, indivíduos, na sua maioria, têm consciência de si mesmos como egos isolados existindo dentro de seus corpos" (Capra, 1983, p. 25). Esse arranjo sintagmático para descrever o mundo é comumente chamado de modernidade: a emergência de uma sociedade aberta à possibilidade de 
mobilidade social na qual as fronteiras não existem e a exterioridade é ignorada. Com o saber laico no lugar do divino, as práticas, assim como as organizações e valores, são regidos pela racionalidade. Nessa sociedade, a ciência dita, e os sábios deliberam sobre o "normal e o patológico" (Gagnon, 1990, p. 79).

Apoiado nas ideais iluministas, e tendo por referência a razão, a modernidade propunha lutar contra o controle arbitrário, contra os preconceitos e contra as contingências da tradição. Na modernidade, o legítimo é o racional. Deus e a tradição devem ser substituídos pela autoridade política exercida pelos homens segundo princípios universalistas, e não segundo interesses pessoais. Entretanto, a realidade sociopolítica do século XX mostrou que o projeto de emancipação social da modernidade, no qual a ciência, a política e as artes indicavam o caminho, revelou-se estéril. O conhecimento científico foi profundamente afetado pelos avanços tecnológicos, fazendo com que ele passasse a ser medido em termos de quantidade de informação: tem maior poder quem sabe mais, e o saber pode ser manipulado (a mídia é o maior exemplo de manipulação da informação).

A chamada pós-modernidade se caracteriza por um descrédito nas ciências como fonte de verdade, pelo fim das metanarrativas (Lyotard, 1979), ou seja, das narrativas totais e globalizantes que ordenam e explicam tanto o conhecimento quanto a experiência, pois os grandes esquemas explicativos nada mais garantem. Passou-se a questionar radicalmente as verdades construídas na modernidade, tais como a crença na razão, na capacidade da ciência em dar respostas, assim como uma suposta linearidade histórica: o trem do tempo, expressão comum no início do século $X X$, teria se descarrilado após a Primeira Grande Guerra. Trata-se de determinar o estatuto do conhecimento nas sociedades pós-industriais, ou seja, de se perguntar em que medida a informatização altera o conhecimento e quais são as consequências políticas daí advindas para a sociedade e para o Estado. Ocorreu o que Lyotard qualifica como "deslegitimação do conhecimento" (p. 38): um conhecimento que se justifica por si mesmo sem nada que o legitime. A grande pergunta passou a ser: quem decide o que é o conhecimento? E, mais ainda: quem sabe como decidi-lo? Quem tem esse controle, detém o poder (exemplo disso é o que aconteceu, há alguns anos, com os cientistas das Agências de Estudos Espaciais de vários países frente a um problema que continua sem resposta: que tipo de triagem operar, e que parâmetros utilizar para fazê-lo, diante das centenas de milhares de informações que Ihes são transmitidas pelos satélites cada vez mais sensíveis e pelos telescópios que veem cada vez mais longe e mais no passado, para decidir quando uma informação recebida deve ser examinada com mais detalhes, ou, ao contrário, quando deve ser abandonada por ser considerada sem interesse? Mais complexo ainda: como detectar as informações que recebem se a noção mesma de informação pode variar segundo as formas de vida que as emitem?

No fundo, o que está em jogo é a relação entre conhecimento, poder e as (novas) formas de controle que daí surgiram. Na era pós-moderna, ocorreu uma emancipação dos domínios de competência, de forma que cada um possui critérios que lhe são próprios. Não existe compatibilidade entre a verdade de discurso científico e a noção do correto em política. Entretanto, as posições de Lyotard, e de outros autores pós-modernos, foram duramente criticadas por vários autores, dentre os quais Callinicos (1995) e Habermas (1987), por verem nas críticas da modernidade referentes ao ceticismo universal nada mais do que uma metanarrativa contemporânea, ou seja, um outro dispositivo de poder. 
Dentre as mudanças que produziram a pós-modernidade, não podemos nos esquecer das grandes polêmicas relativas aos movimentos feministas, à reorganização da família e às regras do matrimônio. Em um primeiro momento, o casamento era um contrato feito segundo interesses mútuos para se manter, ou aumentar, o patrimônio: o sexo e o amor estavam fora da união. A ordem familial burguesa se sustentava em três fundamentos: a autoridade do marido, a submissão da mulher e a dependência das crianças. Os filhos repetiam o destino do pai, e as filhas, o da mãe. O pai, embora todo poderoso, vivia acuado em seu território privado e inacessível. Nessa organização, na qual o único lugar da mulher era tornar-se mãe, a maternidade ganhou um lugar considerável, cabendo à mulher a responsabilidade de zelar pelo bem-estar das crianças, pois são os futuros herdeiros. Se o pai é o provedor, o intelecto, a mãe é, por natureza, a que deve ocupar-se da criança: aos poucos, construiu-se a ideia de que o amor materno é algo instintivo na mulher (Badinter, 1985). Com isso, controlava-se aquilo que, no imaginário masculino, era visto como uma grande ameaça: a irrupção do orgasmo feminino incontrolável, tão bem descrito por Flaubert em Madame Bovary, e que tanto incomoda os psicanalistas com suas infindáveis questões sobre o gozo feminino.

Quando o Estado começou a ocupar-se das crianças, o poder paterno diminuiu, dando início ao declínio do patriarcado, que muitas vezes é confundido com o declínio da função paterna ou do Nome-do-Pai, fazendo surgir uma nova ordem. Com a ingerência do Estado na família, estabelece-se a igualdade entre os filhos, e não há mais filhos ilegítimos: o Estado Ihes garante o direito de ter pai e mãe, assim como o acesso à educação. A imagem do pai dominador cedeu lugar à representação de uma paternidade ética: a do pai que protege os filhos e que se ocupa do sustento do lar. O bom pai cuida dos filhos, que não são mais objetos de sua inquestionável autoridade. Concomitantemente, os movimentos feministas, para os quais a psicanálise deu a sua contribuição, levaram à emancipação da mulher. O aparecimento da pílula anticoncepcional, a chamada revolução sexual dos anos 60, a liberação, em alguns países, do aborto, o morar junto, ter relações sexuais sem que as pessoas envolvidas estivessem casadas, as relações envolvendo pessoas do mesmo sexo a céu aberto e outras tantas manifestações da sexualidade, tudo isso passou a integrar a paisagem social, e teve repercussões nas relações homem/mulher (Ceccarelli, 2008a, 2008b). Aos poucos, a mulher passou a decidir sobre a procriação, e adquiriu o controle sobre o seu corpo e sobre sua sexualidade. O casamento não se moldava mais sobre o contrato, sobre os bens, mas sobre o direito de escolher o(a) parceiro(a). Todavia, a união que repousa sobre o amor não é a mesma, pois o amor não é perene como os bens: aparece então a possibilidade de rompimento da união. A família fundada sobre o amor produz uma transformação radical na sociedade (Roudinesco, 2002). Juntam-se a isso as novas configurações familiares, as novas formas de filiação e de criação dos filhos, que modificam ainda mais esse cenário (Ceccarelli, 2002, 2007).

Reações misóginas prediziam que a mulher que trabalhasse fora, e que tivesse acesso à pílula, estaria mais exposta às tentações de relações extraconjugais. Não faltou quem visse nas novas organizações afetivas o fim da família e a decadência dos costumes e da moral, pois as mudanças nos arranjos familiares estariam ameaçando a ordem social, posto que a participação da família para a manutenção do laço social é fundamental (Ratzinger, 2004). Ainda que se possa concordar com esse argumento, estudos antropológicos mostram que não existe uma definição única de família (Héretier, 1991; Parseval, 2004). Isso significa que, embora uma forma de arranjo social 
entre os indivíduos seja necessária para que a sociedade se mantenha, não existe um modelo único desse arranjo: o que mantém a união entre os sujeitos e possibilita o trabalho de cultura são as ligações pulsionais, ou seja, o trabalho de Eros (Freud, 1930/1974).

A pós-modernidade, com a crise do conhecimento, com o fim das certezas e com as mudanças na estrutura familiar, além de outros fatores, estaria promovendo uma ruptura social e gerando, dentre outras, uma violência sem precedentes. Estaríamos vivendo em uma sociedade fragmentada, na qual existem vários códigos de conduta que não se comunicam. Nessa linha de raciocínio, autores como Lebrun (1997) e Melman (2002) retomam o tema da ruptura do laço social pela via do fim das referências simbólicas, do desaparecimento da função paterna e do nome-do-pai. Argumentam que o desenvolvimento técnico-científico, a valorização do virtual em detrimento do real, devido sobretudo à internet, teriam desacreditado a autoridade paterna no âmago da família, o que estaria impedindo o pai de equilibrar o poder maternal. São trabalhos, enfim, que falam de uma desesperança generalizada na pós-modernidade, e profetizam um futuro catastrófico.

Concordar com tais previsões apocalípticas é esquecer o que a História nos ensina, e, talvez o mais difícil, negar o fato inelutável de que cada época tem a sua própria maneira de ler o mundo sem que uma seja necessariamente melhor que a outra. Aceitar as novas organizações pulsionais geradas pelas mudanças sociais nos obriga a fazer o luto de representações que até então eram tidas como naturais e imutáveis, representações que nos serviam de referências para nos locomovermos no simbólico. Evidencia-se, assim, o caráter imaginário de toda leitura de mundo, provocando o retorno dos eternos questionamentos: quem somos, de onde viemos, para onde vamos, o que nos torna sujeitos, o que vai acontecer diante de tanta mudança. O passado sempre exerceu uma misteriosa atração. Sentimos um forte apelo pelo passado - quando "eu era feliz e ninguém estava morto" (F. Pessoa) - sempre que o presente nos parece doloroso, o que acontece com frequência, na esperança de reencontrarmos a idade de ouro perdida para sempre: "o encantamento de nossa infância, que nos é apresentada por nossa memória não imparcial como uma época de ininterrupta felicidade" (Freud, 1939/1875, p. 89).

Se tomarmos, por exemplo, a violência, constatamos sem dificuldades que ela tem estado presente desde a aurora da humanidade (Ceccarelli, 2006). O livro do Genesis $(4,8)$ nos fala de como a primeira família não escapou à rivalidade dos irmãos, e esse foi o primeiro problema que a jovem espécie humana teve que enfrentar após o assassinato do tirando da horda, "O crime principal e primevo da humanidade" (Freud, 1928/1974, p. 211).

As guerras sempre existiram e civilizações sempre tentaram dominar outras pelo recurso à violência. Os grandes descobrimentos, ou melhor, a conquista das Américas, e mais tarde as catequizações, foram acompanhados de uma virulência que destruiu, e continua a destruir, civilizações e culturas através do mundo. O fanatismo religioso, com o seu cortejo de intolerância que levou milhares de homens e de mulheres à fogueira e à caça às bruxas, continua, ainda que de forma (às vezes) mais velada, presente na atualidade. A ascensão e a queda dos regimes totalitários, igualmente, sempre foram acompanhadas de extrema violência. Os exemplos se multiplicam quando nos lembramos dos conquistadores que marcaram a História, como Alexandre o Grande e Gengis Khan.

Tudo isso leva a pensar que a violência seja uma constante quase universal do estado de cultura. Ela está presente desde sempre 
em toda parte, ainda que alguns fatores, como a difusão de informação em tempo real, o aumento demográfico do Planeta e as desigualdades sociais (a fratura Norte-Sul, mas igualmente as ilegalidades dentro de cada país) sejam variantes que contribuem para globalizar e banalizar a violência, dando-nos a impressão de que ela nunca foi tão grande.

A atualidade apenas reproduz, pela repetição do mesmo sob formas variadas, efeitos enganosos que mascaram, graças ao imaginário cultural no qual o sujeito se encontra submerso em um dado momento sociohistórico, o mal-estar (Unbehagen) inerente à cultura. Cada época, dentro do particular de seu contexto histórico, desvela a violência com a face que lhe é própria. $\mathrm{Na}$ busca de satisfações substitutivas para manter a ilusão de onipotência e negar (Verleugnung) os limites impostos pelo princípio da realidade ao princípio do prazer, a espécie humana sempre reagiu com violência frente a tudo que ameaça seu frágil narcisismo: não mais reconhecemos "sua majestade o Ego, o herói de todo devaneio de todas as histórias" (Freud, 1908/1969a, p. 155). O que está em causa é o que Ehrenberg (2004) chama de “o mito do enfraquecimento da regra social" ( $p$. 140), que nos faz tratar a ordem simbólica como se ela fosse imutável, ou melhor, como se qualquer mudança ameaçasse a ordem pública.

Nossa tendência em atribuir à atualidade uma violência particular se deve a questões eminentemente narcísicas: sentimo-la mais intensa, pois vivemos agora, e é agora que somos ameaçados. Além disso, não temos como saber, por exemplo, se, na Idade Média, quando tudo era garantido e explicado pelos desígnios de Deus, ou na modernidade, quando a ciência nos dava as explicações e garantia um futuro previsível, ou ainda na pós-modernidade, quando não existem garantias, do ponto de vista da dinâmica psíquica, existiriam diferenças no que diz respeito às configurações da angústia. Sem dúvida, "não nos sentimos confortáveis na civilização atual, mas é muito difícil formar uma opinião sobre se, e em que grau, os homens de épocas anteriores se sentiram mais felizes, e sobre o papel que suas condições culturais desempenharam nessa questão" (Freud, 1930/1974, p. 108). Com efeito, que razões temos para acreditar que, quando Deus guiava tudo, os homens eram menos angustiados? De quais elementos dispomos para dizer que o estado de coisas gerado pela perda de certezas da modernidade foi maior, ou menor, do que a passagem do feudalismo ao Estado moderno? Sobre isso, podemos apenas fazer conjecturas. Nessa perspectiva, fica difícil seguir autores como, por exemplo, Lebrun (1997) e Melman (2002), que se perguntam se a psicanálise teria algo a dizer sobre o mal-estar na civilização atual. Como se tivesse existido alguma época sem malestar! Com propriedade, Rennó dos Mares Guia (2007) escreve:

o mal-estar não se limita a uma época ou a uma cultura determinada; não se trata de um diagnóstico da época atual, mas de um conflito entre pulsão e cultura inerente à existência do homem.... Em psicanálise, o mal-estar não caracteriza nem uma época, nem um sintoma. (p. 54)

\section{Mudança de paradigma}

Para além da inegável participação dos avanços científicos no fim das verdades, uma de suas contribuições mais importantes, e que acirrou ainda mais o sentimento de desamparo na contemporaneidade, ainda não foi, na minha opinião, devidamente avaliada: a mudança de nossa percepção da dimensão espaçotempo. A passagem do universo newtoniano para o einsteiniano levou-nos a operar uma reorganização psíquica em nossa maneira de nos situarmos no mundo, logo, no nosso cotidiano e em nossas práticas profissionais: mudança de paradigma semelhante à 
que, na dimensão psíquica, representou a descoberta do inconsciente. As contribuições da Física quântica e da relativista modificaram inexoravelmente nossa relação com o tempo de tal forma que a noção de tempo que temos não guarda nenhuma semelhança com a noção de tempo de outras épocas.

Um dos exemplos mais pungentes é a internet e as modificações que ela produziu em nossa relação com os acontecimentos mundiais. Seu desenvolvimento - assim como o do raio laser, microondas, computadores... e a lista é infinda - só foi possível graças à conquista do átomo. O espaço, o tempo e a distância parecem deixar de existir, pois que o fato ocorra na sala ao lado ou do outro lado do Planeta, ontem, hoje ou amanhã (dependendo de onde estamos no globo) passa a ter pouca importância: todos os que estão plugados o acessam em tempo real. Entretanto, a despeito de tanta tecnologia, a sensação é de termos cada vez menos tempo!

Se o tempo é uma abstração dos processos secundários, que são influenciados pelos elementos do mundo externo, nossa apreciação do tempo está profundamente ligada ao momento histórico no qual estamos inseridos. Não há como conciliar, porém, a temporalidade dos processos secundários com a atemporalidade do inconsciente. E é por isso que as representações e dispositivos que criamos desde que fomos marcados pelo estado de cultura para suportar a angústia inerente ao desamparo (Hilflosigkeit) psíquico são, por definição, fadados ao fracasso. As contribuições de Aulagnier (2004) complicam ainda mais a questão do tempo. Com a noção de antecipação, esse autor propõe que o futuro psíquico da criança é profundamente determinado por um passado (o passado dos pais) que lhe é totalmente desconhecido e nada tem a ver com o tempo cronológico. Em outras palavras, para que o sujeito se constitua, ele deve ser antecipado por aqueles (as) que lhe darão vida psíquica.
Como seres históricos, todos nós, psicólogos ou não, somos afetados pelos mesmos movimentos responsáveis pelas reorganizações psíquicas, por isso não temos como saber, no sentido de vivenciar, por exemplo, a significação profunda das queixas dos clientes de Freud, simplesmente por desconhecermos a dinâmica pulsional daquela época. Nossas teorias, independentemente da linha que seguimos, sofrem os efeitos das mudanças contemporâneas. Assim, embora o complexo de Édipo seja universal e atemporal, sua compreensão só pode ser corretamente avaliada levando-se em conta o momento sociohistórico e a ordem simbólica que organizam a circulação dos afetos assim como a singularidade das normas e sanções sociais, nas quais a criança se encontra inserida.

O objetivo dessa digressão foi o de mostrar que desde sempre o ser humano recorreu aos mais diversos recursos, tanto internos quanto externos, para lidar com o seu desamparo (Hilflosigkeit) constitucional. Ao falar do desamparo, não me refiro ao "longo período de tempo durante o qual o jovem da espécie humana está em condições de desamparo e dependência" (Freud, 1926/1976, p. 179), mas de um outro capaz de realizar uma ação específica que aliviará a tensão interna, de uma outra forma de desamparo bem menos discutida: o desamparo psíquico, pois, desde o começo da vida, o jovem da espécie humana não tem como lidar com as demandas pulsionais filogeneticamente herdadas (Freud, 1915/1987). Uma das astúcias utilizadas pelo Eu em constituição para lidar com a angústia oriunda do desamparo psíquico é utilizar-se dos elementos do imaginário social da cultura no qual está inserido para dar representações às pulsões. O universal do desamparo se singulariza na história de cada um, a partir da relação que a criança estabelece com quem lhe deu vida psíquica, devido à total dependência da criança em relação aos pais, pois "estávamos certos de sua proteção contra os perigos" (Freud, 1927/1974, p. 28). Quando 
É interessante lembrar que a força pulsional que alimenta o movimento histórico tem suas raízes nas teorias sexuais infantis (Freud, 1905/1972). adultos, reagimos às inevitáveis situações de desamparo ao longo da vida, segundo o protótipo infantil: frente às manifestações de angústia, o sujeito encontrará alento em seu mundo interno ou procurará respostas nas construções simbólicas que o (seu) mundo externo lhe oferece. Insisto neste ponto: embora as representações oferecidas ao sujeito para lidar com o desamparo psíquico variem segundo a cultura e o momento histórico, a necessidade de respostas que o confortem é um fator presente desde sempre na história humana.

Resumindo até aqui: como mostra a história libidinal da humanidade, o fato mesmo de que os dispositivos que criamos para nos confortar tenham sempre falhado em cumprir esse objetivo atesta que nada, nenhuma organização psicossocial, nenhuma crença, nenhuma ciência, ou, se preferirmos, nenhum objeto, nos protege do desamparo: cada época tem a sua metanarrativa. Se, ao longo da história, o ser humano tivesse encontrado algo que o satisfizesse, o que chamamos de movimento histórico nunca teria acontecido. É interessante lembrar que a força pulsional que alimenta o movimento histórico tem suas raízes nas teorias sexuais infantis (Freud, 1905/1972). A existência desse movimento nos mostra que o desamparo sempre faz retorno, e que cada época se utiliza dos meios que tem para enfrentá-lo: os expedientes que encontramos para nomear o que nos aflige variam segundo o discurso dominante do momento sociohistórico no qual estamos inseridos. E de tais discursos se originam as diferentes versões da ordem repressiva.

\section{Esboços de uma nova ordem repressiva}

Se, como vimos, sempre precisamos de teorias e explicações para nos localizarmos e nos deslocarmos no mundo, seria interessante tentar entender quais são os instrumentos teórico-clínicos utilizados atualmente para cumprir essa finalidade e, ao mesmo tempo, o perigo de que esses instrumentos se transformem em formas de controle.

A Psicologia pode contribuir, ainda que indiretamente, para a construção de uma ordem repressiva quando, por exemplo, suas teorias se transformam em instrumentos tecnológicos. Cada vez mais os profissionais do psiquismo vêm sendo convocados no espaço público para opinarem sobre diversos temas sociais. Hoje em dia, graças ao trabalho dos psicólogos e do Sistema Conselhos, estamos presentes em vários segmentos da sociedade e participamos, às vezes como membros efetivos, dos comitês que debatem ética, violência, clonagem, saúde mental, planejamento familiar, adoção, as novas organizações familiares, a diversidade sexual, e outros tantos. Não raro, ouvirmos posicionamentos que apresentam as teorias psicológicas como detentoras de verdades e guardiãs de uma ordem simbólica imutável, o que Ihes daria o poder (perverso) de deliberar sobre o normal e o patológico. Que fique claro: acho que a participação dos psicólogos é de fundamental importância nas discussões sobre os temas que afetam o tecido social, e, por isso, devemos nos pronunciar quando convocados a fazê-lo, mas debater não significa nos valermos de nossas teorias para receitarmos, de forma normativa e generalizada, que cuidados devem ser tomados para um desenvolvimento normal. A verdadeira contribuição da Psicologia é a de analisar as mudanças na dinâmica dos elementos que estão sendo discutidos, para tentar compreender como a ordem simbólica pode, ou não, ser afetada pelas mudanças sociais. Lembrando um texto apresentado por Bock em 2002, não existe clínica psicológica sem consequências, pois nossas intervenções são, inevitavelmente, direcionamentos: nossa prática profissional transforma os sujeitos. Isso significa que, implícita ou explicitamente, nossa atuação 
profissional reflete um projeto político, logo, uma construção social que pode ser transformada em instrumento ideológico a serviço de uma ordem repressiva. Com que ouvido escutamos, atuamos e transformamos o sofrimento psíquico? Que compreensão temos de sua origem e, por conseguinte, em que direção vamos intervir?

Outra grande fonte geradora de controle é a questão de como a saúde psíquica tem sido tratada a partir dos DSMs. O interessante sobre esse ponto é que as críticas mais recentes têm sido feitas não pelos psiquiatras, aparentemente comprometidos com os ditames dos laboratórios farmacêuticos, mas por historiadores e escritores.

É o caso do livro de Christopher Lane, crítico literário, historiador anglo-americano e professor na Northwestern University, publicado em setembro de 2007, intitulado Shyness: How Normal Behavior Became a Sickness (Timidez: como o comportamento normal se tornou uma doença). Graças ao acesso privilegiado aos arquivos da Associação Americana de Psiquiatria e aos relatórios de executivos de empresas farmacêuticas, Lane nos revela a realidade perturbadora dos labirintos dos transtornos mentais: com pouca justificação científica, e com bases no mínimo divertidas, senão ridículas e improváveis, inúmeras emoções e sentimentos - dentre as quais a timidez - entraram para o rol das desordens psiquiátricas e, logo, são passíveis de responder ao tratamento com psicotrópicos. Com sagacidade, o livro de Lane desmonta a fachada da pesquisa objetiva e mostra que diagnosticar os transtornos mentais se tornou um negócio altamente rentável, cuja subvenção e monopólio pertencem aos gigantes da indústria farmacêutica, com o apoio da onipotente FDA (Administração de Alimentos e Medicamentos) norte-americana, sendo que essas organizações se beneficiam, além disso, da conivência das universidades, da cumplicidade das mídias e do enorme poder persuasivo das agências de publicidade. Todas essas estratégias reescreveram radicalmente a história da psiquiatria, como se Charcot, Freud, Jaspers e outros tantos nunca tivessem existido.

Antes de lançar um medicamento no mercado, observa Lane, é necessário criar a doença para a qual ele será útil. Foi o caso do transtorno de ansiedade social, a patologia vedete nos Estados Unidos, que, segundo o DSM (Manual Diagnóstico e Estatístico de Desordens Mentais), se caracteriza indiferentemente pela timidez, pelo medo de urinar em lavabos públicos ou simplesmente de cometer uma gafe. Lane demonstra como o DSM elaborado pela APA (Associação Americana de Psiquiatria) e atualmente utilizado em todo mundo graças à OMS (Organização Mundial de Saúde) fez com que, em 30 anos, emoções banais fossem transformadas em doenças mentais, permitindo, assim, que a indústria farmacêutica rentabilizasse as moléculas inúteis.

A quinta edição do DSM (DSM-V), prevista para 2012, traz novas síndromes (rebatizadas adições) tais como uma atividade sexual excessiva, a apatia, o amor pela gastronomia, o fato de beber um copo de vinho por dia ou ainda o prazer de surfar por horas na internet. Aos distúrbios, juntam-se o medo de atravessar uma estrada em um lugar perigoso, a angústia de morrer quando se descobre portador de uma doença incurável e o temor de perder o emprego em tempo de crise. "Graças ao DSM", observa Elisabeth Roudinesco (2009), "somos convidados a nos considerar doentes mentais, perigosos para os outros e para nós mesmos. Tal é a vontade higienista e securitária da grande bíblia da psiquiatria moderna".

Cabe-nos reagir a tudo isso com certa ironia e, retornando à questão, perguntarmos onde nós, estudiosos do psiquismo, nos encaixamos 
nesse infindável inventário de emoções, hábitos e comportamentos. Afinal, ainda que (talvez) de forma menos aditiva do que a dos membros dos comitês do DSM que dedicaram anos a classificar e a etiquetar a diversidade humana, muitos de nós nos dedicamos exaustivamente ao trabalho, passamos os dias ouvindo o sofrimento dos outros, as noites nas reuniões das associações e das sociedades e, nos eventuais encontros de finais de semana com os colegas, isso quando o tempo permite, continuamos falando das mesmas coisas.

Ainda no plano coletivo, a nova ordem repressiva se expressa de várias maneiras, sendo uma das mais evidentes na área da sexualidade. Se, de um lado, a revolução sexual dos anos 60 trouxe maior liberação das práticas sexuais, por outro lado, observase que a moral sexual civilizada continua em pleno vigor nas inúmeras versões do politicamente correto. Não se trata do discurso, denunciado por Foucault em sua História da Sexualidade, que visa ao controle do indivíduo e da população, mas, antes, de transformar os atos banais em assédio sexual. Exemplos não faltam: em certos Estados norte-americanos, olhar alguém em um elevador de certa maneira - sempre difícil de precisar -, ou, ainda, deixar que certas partes das roupas íntimas apareçam, tal como a alça de um sutiã, pode transformar-se em delito a ser resolvido no tribunal. Recentemente, ainda nos USA, uma campanha foi efetuada a fim de convencer as mães a não amamentar os filhos no peito, privadamente ou em público, devido à possibilidade de que esse ato desperte prazer erótico nos protagonistas, mas, sobretudo, na mãe.

$\mathrm{Na}$ época do politicamente correto, se colocarmos certas passagens do Três Ensaios sobre a Teoria da Sexualidade, de Freud, ou da Psychopathia Sexualis, de Krafft-Ebing, na internet, sem precisar o nome dos autores, provocaríamos uma verdadeira caça ao perverso que teria escrito tais propósitos infames. Brincar com uma criança, fazer um comentário lisonjeiro sobre um(a) adolescente pode ser indício de pedofilia latente.

Certas igrejas evangélicas extraem a força para manter seus fiéis da repressão da sexualidade genital, que em nada deixa a desejar ao discurso medieval. Há pouco tempo, saiu uma nova versão da Bíblia, na qual foi introduzida a palavra homossexualidade, noção inexistente na Antiguidade, para falar das práticas abomináveis aos olhos de Deus. Nessa mesma versão, quando das Bodas de Caná, Cristo teria transformado a água em suco de uva, e não em vinho, visto que, para certas confissões religiosas, o álcool é radicalmente proibido.

Ainda em relação à sexualidade, existe o outro aspecto, que pouco se leva em conta e que, além de preocupante, contribui para o estabelecimento da nova ordem repressiva: o fato de se negligenciar, às vezes mesmo ignorar, que a criança possui uma sexualidade e um universo fantasmático. Uma dramática ilustração dessa situação foi o que ficou conhecido como o caso de Outreau, nome da cidade na região de Boulogne-sur-Mer, no norte da França, onde ocorreu um dos maiores enganos judiciários da história daquele país (Aubenas, 2005; Guyomard, 2009; Wiel, 2006).

Entre 2001 e 2006, Outreau foi objeto de uma forte exposição midiática devido às denúncias que envolviam 17 adultos em atos e orgias pedófilas praticadas com inúmeras crianças entre 4 e 14 anos. No final, tratava-se de um sórdido caso de incesto em que, de fato, um pai abusara regularmente do filho com a cumplicidade da esposa. Todo o resto não passou de uma grande histeria coletiva, uma variante moderna das bruxas de Salém: em ambos os acontecimentos, o demônio foi a sexualidade. No caso de Outreau, com a pedofilia no lugar do demônio, as 
fantasias sexuais, tanto de adultos quanto de crianças, foram tomadas por realidade e transformadas em peças de convicção. A cegueira generalizada produzida pelo surgimento do aspecto sexual foi tal que, por muito tempo, passou despercebido que uma das crianças que supostamente sofrera de abusos sexuais não tinha sequer nascido quando os fatos ocorreram! Cômputo final: um suicídio, treze inocentados dentre os dezessete acusados, famílias destruídas, crianças traumatizadas, carreiras arruinadas. E, por fim, as acusações de abuso sexual que pesavam há mais de quatro anos sobre o padre Dominique Wiel caíram quando as duas crianças que o acusavam se retrataram admitindo terem mentido.

O que chama a atenção nesse caso é que as crianças que realmente sofreram abuso já tinham sido encaminhadas anteriormente ao hospital local por violências por parte dos pais, mas as queixas só foram ouvidas quando se passou a falar de violência sexual. O juiz de instrução, que mais tarde foi julgado pelo CSM (Conselho Superior de Magistratura) por falta evidente de rigor e de imparcialidade na instrução do inquérito, partiu do princípio que, na ausência de provas materiais, a palavra das crianças é soberana, pois elas jamais mentem. Constatase, mais uma vez, o quanto a sexualidade é problemática, sobretudo a infantil. Tomar sempre como verdade factual tudo o que as crianças dizem sob o pretexto que elas dizem sempre a verdade é esquecer a dimensão fantasmática da sexualidade, ou seja, as fantasias de sedução. Se, é verdade, muito se ganhou a partir do momento em que o Estatuto da Criança e do Adolescente os protege dos abusos dos pais, o caso de Outreau é exemplar no sentido de lembrar que as instâncias jurídicas são compostas de sujeitos que, como qualquer sujeito, possuem um inconsciente.

Em certos meios psicanalíticos, é comum escutarmos que não encontramos mais os pacientes histéricos descritos por Freud, e, na atualidade, a clínica é a da perversão. Ainda que, de fato, seja rara a conversão histérica da época de Charcot, parece estarmos frente a um fenômeno de histeria coletiva que transformou a palavra perverso/perversão em uma espécie de senha, um fetiche a ser usado quando o profissional se encontra frente a um sujeito cujo funcionamento psíquico ele não consegue entender. Nas escolas, as crianças que não se enquadram nas normas são rapidamente diagnosticadas como problemáticas e, não raro, medicadas. É cada vez maior o número de trabalhos psicopedagógicos em que o rótulo perverso é aplicado, e um comportamento provocativo e desafiador da criança é teorizado como gozo, sem que uma pesquisa mais detalhada da dinâmica psíquica que a afeta seja realizada.

\section{Reflexões finais}

Esses elementos fornecem as bases para o surgimento da nova ordem repressiva: uma forma discursiva que, muitas vezes apoiada em bases científicas, transforma as singularidades em anomalias, os atos espontâneos em desvios, uma ordem que trata o universo fantasmático (subjetivo) como realidade objetiva, e que não leva em conta que a sexualidade adulta, por mais normal que seja, se apoia na polimorfia perversa da sexualidade infantil. Ainda que não se possa negar a presença de desejos incestuosos recalcados nas relações adulto/criança, a verdadeira perversão consiste em só enxergar, em tais relações, componentes de ordem sexual: de que lado está a perversão?

A subjetividade vem perdendo terreno, e cada vez mais tudo é explicado pela genética, o que pode servir aos fins de controle - conhecemos as consequências do eugenismo - e para enriquecer ainda mais a indústria farmacêutica. As imagens cerebrais feitas por sofisticadas técnicas de ressonância magnética, que permitem ver desde a insônia 
a dores lombares, passando pelo estresse e pelo pensamento, aumentam a eficácia do diagnóstico sem que a história do sujeito seja levada em conta.

O uso de nomenclaturas para designar a diversidade do sofrimento humano tem se imposto cada vez mais, tornando-se a moeda de troca da nova vaga de profissionais formados nos DSMs. Os psicólogos não estão ao abrigo dessa situação, sobretudo quando se levam em conta os desdobramentos do ato médico.

Todos esses exemplos, aos quais poderíamos acrescentar muitos outros, mostram a necessidade humana de buscar referências externas para nomear o que desconhecemos internamente. Como dissemos, não temos como escapar desse processo, pois é através dele que adquirimos os elementos identificatórios necessários à constituição do Eu e encontramos as representações que nos ajudam a suportar o desamparo psíquico. Entretanto, o discurso que utilizamos para fazê-lo pode facilitar a circulação dos afetos, propiciando maior expressão da diversidade e da diferença ou, ao contrário, limitar essa circulação e/ou definir como ela deve ocorrer, o que pode levar a formas de controle e de repressão.

Para concluir, uma pergunta: o que fazer para barrar essa nova ordem repressiva que está patogenizando a existência comum dos homens e transformando as doenças da alma em sombrios quadros psiquiátricos? 


\section{Referências}

Aubenas, F. (2005). La méprise: L'affaire d'Outreau. Paris: Seul.

Aulagnier, P. (2004). L' apprenti-historien et le maître-sorcier Paris: PUF.

Bock, A. (2002). Em defesa da perspectiva histórica na psicologia. Trabalho apresentado na PUC-MG.

Badinter, E. (1985). Um amor conquistado: o mito do amor materno. Rio de Janeiro: Nova Fronteira.

Callinicos, A. (1995). Theories and arratives: Reflections on the philosophy of history. Cambridge: Polity Press.

Capra, F. (1983). O tao da física. São Paulo: Cultrix.

Ceccarelli, P. R. (2002). Configurações edípicas da contemporaneidade: reflexões sobre as novas formas de filiação. Pulsional Revista de Psicanálise, 161(25), 88-98.

Ceccarelli, P. R. (2006). Violência e cultura. In A. Rudge (Ed.), Traumas (pp. 111-123). São Paulo: Escuta.

Ceccarelli, P. R. (2007). Novas organizações familiares: mitos e verdades. Jornal de Psicanálise, 40(72), 89-102.

Ceccarelli, P. R. (2008a). Transexualismo. São Paulo: Casa do Psicólogo

Ceccarelli, P. R. (2008b). Onde se situa a diferença? Polêmica: Revista Eletrônica do Laboratório de Estudos Contemporâneos, 7(4). Recuperado em 14 de março de 2009, de http://www. polemica.uerj.br/7(4)/lipis4.htm

Ehrenberg, A. (2004). Les changements de la relation normal/ pathologique. A propos de la souffrance psychique et de la santé mentale. Esprit, 5(304), 133-156.

Foucault, M. (2000). Microfísica do poder. Rio de Janeiro: Graal.

Flandrin, J.-L. (1986). La doctrine chrétienne du mariage. Le sexe et l'occident. Paris: Seuil.

Freud, S. (1972). Três ensaios sobre as teorias sexuais. In S. Freud, Edição standard brasileira das obras psicológicas completas de Sigmund Freud (J. Salomão, trad., Vol. 7, pp. 123-250). Rio de Janeiro: Imago. (Trabalho original publicado em 1905)

Freud, S. (1969a). Escritores criativos e devaneios. In S. Freud, Edição standard brasileira das obras psicológicas completas de Sigmund Freud (J. Salomão, trad., Vol. 9, pp. 147-158). Rio de Janeiro: Imago. (Trabalho original publicado em 1908)

Freud, S. (1969b). Moral sexual 'civilizada' e doença nervosa moderna. In S. Freud, Edição standard brasileira das obras psicológicas completas de Sigmund Freud (J. Salomão, trad. Vol. 9, pp. 185-208). Rio de Janeiro: Imago. (Trabalho original publicado em 1908)

Freud, S. (1974). O futuro de uma ilusão. In S. Freud, Edição standard brasileira das obras psicológicas completas de Sigmund Freud (J. Salomão, trad., Vol. 21, pp. 13-71). Rio de Janeiro: Imago. (Trabalho original publicado em 1927)

Freud, S. (1974). Dostoievski e o parricídio. In S. Freud, Edição standard brasileira das obras psicológicas completas de Sigmund Freud (J. Salomão, trad., Vol. 21, pp. 203-223). Rio de Janeiro: Imago. (Trabalho original publicado em 1928)

Freud, S. (1974). O mal-estar na civilização. In S. Freud, Edição standard brasileira das obras psicológicas completas de Sigmund Freud (J. Salomão, trad., Vol. 21, pp. 75-171). Rio de Janeiro: Imago. (Trabalho original publicado em 1930

Freud, S. (1975). Moisés e monoteísmo. In S. Freud, Edição standard brasileira das obras psicológicas completas de Sigmund Freud (J. Salomão, trad., Vol. 23, pp. 13-163). Rio de Janeiro: Imago. (Trabalho original publicado em 1939)

Freud, S. (1976). Inibições, sintomas e ansiedade. In S. Freud, Edição standard brasileira das obras psicológicas completas de Sigmund Freud (J. Salomão, trad., Vol. 20, pp. 95-200). Rio de Janeiro: Imago. (Trabalho original publicado em 1926)

Freud, S. (1987). Neuroses de transferência: uma síntese (I. Salomão, trad.). Rio de Janeiro: Imago. (Trabalho datado de 1915, não publicado, encontrado em 1985)

Gagnon, S. (1990). Plaisir d'amour et crainte de Dieu: sexualité et confession au Bas-Canada. Leval: Presses Université.

Guyomard, P. (2009). Les enfants ne mentent pas. In J. André (Ed.), Désirs d'enfant (pp. 123-137). Paris: PUF.

Habermas, J. (1987). Morale et communication. Paris: Editions du Cerf.

Héritier, F. (1991). Famille. In B. Pierre \& I. Michel, (Ed.). Dictionnaire de l'ethnologie et de l'anthropologie (pp. 273274). Paris: PUF.

Lane, C. (2007). Shyness: How normal behavior became a sickness. New Haven: Yale University Press.

Lebrun, J.-P. (1997). Un monde sans limite. Essai pour une clinique psychanalytique du social. Paris: Erès.

Lyotard, J.-F. (1979). La condition postmoderne. Paris: Minuit.

Melman, C. (2002). L'homme sans gravité: Jouir à tout prix. Paris: Folie Essais.

Parseval, G. (2004). La part du père. Paris: Points Essais.

Ratzinger, J. (2004). Carta aos Bispos da Igreja Católica sobre a colaboração do homem e da mulher na lgreja e no mundo. Recuperado em 23 de novembro de 2004, de http://www.defesadavida.com/colaboracaohomem.htm

Rennó dos Mares Guia, E. (2007). Réflexions sur les constructions psychanalytiques et l'actualité: comment aborder les nouvelles impasses que la réalité pose à la psychanalyse? Mémoire en Master 2 Recherche: Psychologie, Clinique du corps et anthropologie psychanalytique, Paris VII, Paris.

Roudinesco, E. (2002). La famille en désordre. Paris: Fayard.

Roudinesco, E. (2009, 06 de março). La maladie de la médicalisation. Le monde des livres. Le Monde. Recuperado em 10 de março de 2010, de http://www.lemonde.fr/cgi-bin/ ACHATS/acheter.cgi $?$ offre $=$ ARCHIVES\&type item $=$ ART ARCH_30J\&objet_id $=1073155$

Wiel, D. (2006). Que Dieu ait pitié de nous. Paris: Oh! 